\title{
ACTIVATION OF SINABUNG MOUNT VOLCANIC ASH USING VARIOUS MINERAL ACIDS
}

\author{
Shohihatun Bariyah and Lisnawaty Simatupang* \\ Chemistry Department, Faculty of Mathematics and Sciences, Medan State University, Medan \\ 20221, Indonesia \\ *Email: lisnawaty@unimed.ac.id
}

\begin{abstract}
The effect of various types of mineral acids in activating the silica of volcanic ash of Mount Sinabung has been carried out. The use of various types of mineral acids is aimed at reducing impurities in the form of metals contained in the ash so that it can increase the $\mathrm{SiO}_{2}$ content in the ash. In the treatment, volcanic ash is prepared beforehand by grinding and sieving with a 200 mesh sieve. The sieved ash was then added with mineral acids, namely $\mathrm{HCl}, \mathrm{HNO}_{3}$ and concentrated $\mathrm{H}_{2} \mathrm{SO}_{4}$ and heated at $100^{\circ} \mathrm{C}$ for 2 hours. After that, it was neutralized with distilled water and in an oven at $120^{\circ} \mathrm{C}$ for 6 hours and characterized using XRF to determine the impurities that had been lost. Based on the results obtained using XRF characteristics, the $\mathrm{SiO}_{2}$ content of volcanic ash activated with $\mathrm{HCl}$ was $80,23 \%, \mathrm{HNO}_{3}$ was $77,23 \%$ and $\mathrm{H}_{2} \mathrm{SO}_{4}$ was $76,89 \%$. This shows that activation using $\mathrm{HCl}$ is more optimal than using $\mathrm{HNO}_{3}$ and $\mathrm{H}_{2} \mathrm{SO}_{4}$.
\end{abstract}

Keyword : Volcanic ash mount Sinabung, X-ray fluorescence, Activation, Mineral Acid, $\mathrm{SiO}_{2}$

\section{Pendahuluan}

Gunung Sinabung adalah gunung api stratovolkano (berbentuk kerucut) yang terletak di Provinsi Sumatera Utara tepatnya di dataran tinggi Kabupaten Karo. Gunung Sinabung mulai erupsi pada periode tanggal 27 Agustus 2010 sampai 7 Septrember 2010. Selama periode tersebut terjadi tujuh kali erupsi. Gunung Sinabung kembali mengalami beberapa kali erupsi pada periode bulan September sampai Oktober 2013 dan pada periode bulan Januari sampai dengan 29 Juni 2014. Gunung Sinabung terakhir tercatat aktif kembali (erupsi) pada bulan Mei 2019. Meletusnya gunung Sinabung merupakan sebuah bencana dan ancaman bagi masyarakat sekitar, dikarenakan banyak rumah dan lahan pertanian rusak akibat erupsi gunung Sinabung tersebut. Hasil erupsi gunung Sinabung tersebut mengeluarkan kabut asap yang tebal berwarna hitam disertai hujan pasir dan abu vulkanik yang menutupi ribuan hektar tanaman para petani yang berjarak dibawah radius enam kilometer tertutup debu tersebut. Debu vulkanik mengakibatkan tanaman petani yang berada di lereng gunung banyak yang mati dan rusak.

Selain berdampak negatif bagi lingkungan, debu atau abu vulkanik yang dihasilkan dari erupsi gunung Sinabung yang sangat berlimpah juga bisa dimanfaatkan karena kandungan kimiawi yang ada dalam abu vulkanik tersebut. Abu vulkanik merupakan fragmen magma dan terdiri dari mineral, kaca vulkanik dan juga material yang mengandung silika dengan kadar tinggi dan aluminium. Rauf dkk menemukan unsur-unsur yang terkandung dalam material erupsi gunung Sinabung, hasil analisis menunjukkan, sifat kimia debu vulkanik hasil erupsi gunung Sinabung 
tergolong masam dengan $\mathrm{pH}$ 4,30-4,98. ${ }^{1-4}$ Abu vulkanik yang dihasilkan oleh letusan gunung Sinabung pada tanggal 11 Januari 2014 memiliki kandungan kimiawi utama berupa $\mathrm{SiO}_{2}, \mathrm{Al}_{3} \mathrm{O}_{2}$, $\mathrm{CaO}$, dan $\mathrm{Fe}_{\mathrm{x}} \mathrm{O}_{\mathrm{y}}$ masing-masing sebesar 58,1\%, 18,3\%, 8,05\% dan 7,09\%. ${ }^{5}$ Kandungan $\mathrm{SiO} 2$ abu vulkanik yang melimpah dapat digunakan sebagai bahan pembuatan adsorben silika.

Penelitian mengenai pengaruh $\mathrm{HCl}$ untuk aktivasi silika dalam ampas tebu telah dilakukan oleh Norsuraya dkk dengan menggunakan $\mathrm{HCl}$ untuk aktivasi (purifikasi) melalui metode perendaman. Hasil menunjukkan bahwa abu ampas tebu setelah diaktivasi sebesar $88,13 \%$ dan memiliki surface area sebesar $466 \mathrm{~m}^{2} / \mathrm{g}$. ${ }^{6}$ Sriyanto dan Darwanta berhasil mempurifikasi silika abu sekam padi dengan memvariasikan asam $\mathrm{HCl}$, $\mathrm{HNO}_{3}$, dan $\mathrm{H}_{2} \mathrm{SO}_{4}$. Hasil penelitian bahwa asam sulfat memiliki pemurnian kadar silika yang tinggi sebesar 99,48\%, sedangkan asam klorida dan asam nitrat sebesar 99,35\% dan 99,38\%. ${ }^{12}$ Lisnawaty telah meneliti kadar silika abu vulkanik sinabung dengan menggunakan karakterisasi XRF dengan mengunakan $\mathrm{HNO}_{3}$ menghasilkan kadar silika sebesar 42,65\%10 dan 69,82\% menggunakan $\mathrm{HCl}_{4}$ untuk aktivasi abu vulkanik gunung Sinabung.

Berdasarkan uraian diatas, dapat dilakukan penelitian tentang peningkatan kadar silika pada abu vulkanik gunung Sinabung dengan memvariasikan asam yang mana asam yang digunakan merupakan asam mineral dengan batasan asam yaitu asam klorida $(\mathrm{HCl})$, asam nitrat (HNO3) dan asam sulfat $\left(\mathrm{H}_{2} \mathrm{SO}_{4}\right)$.

\section{Metodologi Penelitian}

\subsection{Bahan}

Bahan yang digunakan adalah abu vulkanik gunung Sinabung yang diambil dari Desa Berastepu 1,5 km dar puncak gunung sinabung, Karo. Asam asam klorida $(\mathrm{HCl})$, asam nitrat $\left(\mathrm{HNO}_{3}\right)$ dan asam sulfat $\left(\mathrm{H}_{2} \mathrm{SO}_{4}\right)$ masing-masing dengan konsentrasi pekat serta akuades

\subsection{Alat}

Alat yang digunakan yaitu gelas beaker 250 $\mathrm{mL}$, magnetic stirrer, hot plate, aluminium foil, kertas wattman 42, corong Buchner, erlenmeyer leher, dan vakum

\subsection{Prosedur Penelitian}

2.2.1. Preparasi Abu Vulkanik Gunung Sinabung
Dalam penelitian ini menggunakan metode yang dilakukan Simatupang dkk, dengan beberapa modifikasi10. Penelitian ini dilakukan di Laboratorium Penelitian Jurusan Kimia FMIPA Universitas Negeri Medan.

Abu vulkanik yang digunakan dalam penelitian ini diambil dari Desa Berastepu, Kecamatan Simpang Empat, Kabupaten Karo (radius 1,5 km). Abu vulkanik digerus kemudian diayak dengan ayakan 200 mesh untuk menghomogenkan ukuran abu dan memperluas permukaan abu sehingga sintesis natrium silikat efektif.

\subsubsection{Aktivasi Abu Vulkanik Gunung Sinabung}

Sebanyak $20 \mathrm{~g}$ abu vulkanik berukuran 200 mesh direndam dalam $\mathrm{HCl}, \mathrm{H}_{2} \mathrm{SO}_{4}$ dan $\mathrm{HNO}_{3}$ pekat sebanyak $150 \mathrm{~mL}$ selama 2 jam sambil diaduk dengan magnetic stirrer dengan suhu $100 \mathrm{oC}$ dan kecepatan $250 \mathrm{rpm}$ kemudian didiamkan selama 24 jam. Setelah itu abu dinetralkan dengan akuades dan dikeringkan dalam oven pada temperatur $120^{\circ} \mathrm{C}$ selama 6 jam. Kemudian abu vulkanik didinginkan menggunakan desikator dan ditimbang berat keringnya. Setelah itu dikarakterisasi menggunakan XRF untuk mengetahui unsur apa yang ada didalam abu vulkanik tersebut dan mengetahui pengotor yang telah hilang. Setelah abu di XRF dan diketahui pelarut apa yang paling efektif untuk menghilangkan pengotor didalamnya.

\section{Hasil dan Diskusi}

3.1 Preprasi Abu Vulkanik Gunung Sinabung

Preparasi abu vulkanik gunung Sinabung dilakukan sebagai tahap awal dalam penelitian ini. $\mathrm{Abu}$ vulkanik yang digunakan berasal dari Desa Berastepu radius $1.5 \mathrm{~km}$ dari puncak gunung Sinabung, Kabupaten Karo, Sumatera Utara. Sebelum digunakan, abu vulkanik dikeringkan dalam oven dengan suhu $120^{\circ} \mathrm{C}$ selama 6 jam untuk menghilangkan kadar air dalam abu tersebut. Setelah kering abu vulkanik kemudian digerus dan diayak dengan ayakan 200 mesh. Tujuan dari pengayakan ini untuk menghomogenkan ukuran dan memperluas permukaan abu vulkanik tersebut.

\subsection{Aktivasi Silika Dengan Berbagai Asam Mineral \\ Pada tahap proses aktivasi silika ini} menggunakan berbagai jenis asam mineral. Asam mineral yang digunakan yaitu asam klorida $(\mathrm{HCl})$ 
pekat, asam nitrat $\left(\mathrm{HNO}_{3}\right)$ pekat dan asam sulfat $\left(\mathrm{H}_{2} \mathrm{SO}_{4}\right)$ pekat. Tujuan dilakukan penggunaan tiga jenis asam mineral ini adalah untuk mengetahui asam yang paling bagus untuk digunakan pada proses pembuatan natrium silikat. Untuk mengetahui itu, dilihat dari berapa kadar silika yang teraktivasi dalam asam mineral tersebut.

Abu vulkanik yang telah diayak dengan ayakan 200 mesh ditimbang sebanyak 20 gram dan didestruksi dengan masing-masing larutan $\mathrm{HCl}$, $\mathrm{HNO}_{3}$ dan $\mathrm{H}_{2} \mathrm{SO}_{4}$. Abu vulkanik didestruksi dengan larutan asam ini bertujuan untuk menghilangkan pengotor berupa logam-logam yang terkandung di dalam abu tersebut5. Penggunaan $\mathrm{HCl}, \mathrm{HNO}_{3}$ dan $\mathrm{H}_{2} \mathrm{SO}_{4}$ dalam proses pemurnian dikarenakan sifat kimia $\mathrm{SiO}_{2}$ tidak larut/reaktif terhadap asam kecuali $\mathrm{HF}$, sehingga tidak mengurangi rendemen $\mathrm{SiO}_{2}$ yang terbentuk. Dengan berkurangnya logam pengotor tersebut diharapkan dapat meningkatkan kadar $\mathrm{SiO}_{2}$ di dalam abu. Setelah itu dikeringkan dalam oven dengan suhu $120 \mathrm{oC}$ selama 6 jam untuk menghilangkan kadar air dalam abu tersebut dan didinginkan dengan desikator. Dianalisis kandungan bahan kimianya dengan menggunakan XRF (X-Ray Fluorescence). Kandungan bahan kimia tersaji pada Tabel 4.1 berikut.

Tabel 1. Data XRF abu vulkanik setelah diaktivasi

\begin{tabular}{|c|l|l|l|l|}
\hline \multirow{2}{*}{ No. } & \multirow{2}{*}{$\begin{array}{c}\text { Komposisi } \\
\text { Kimia }\end{array}$} & \multicolumn{1}{|c|}{$\mathrm{Wt}(\%)$} \\
\cline { 3 - 5 } & \multicolumn{1}{|c|}{$\mathrm{HCl}$} & $\mathrm{HNO}_{3}$ & $\mathrm{H}_{2} \mathrm{SO}_{4}$ \\
\hline 1. & $\mathrm{Al}_{2} \mathrm{O}_{3}$ & 10.47 & 12.05 & 12.96 \\
\hline 2. & $\mathrm{SiO}_{2}$ & 80.23 & 77.23 & 76.89 \\
\hline 3. & $\mathrm{~K}_{2} \mathrm{O}$ & 2.25 & 2.02 & 2.04 \\
\hline 4. & $\mathrm{CaO}$ & 3.49 & 4.01 & 4.38 \\
\hline 5. & $\mathrm{TiO}_{2}$ & 0.25 & 0.45 & 0.37 \\
\hline 6. & $\mathrm{MnO}_{2}$ & 0.78 & 0.13 & 0.13 \\
\hline 7. & $\mathrm{Fe}_{2} \mathrm{O}_{3}$ & 1.98 & 4.02 & 3.14 \\
\hline 8. & $\mathrm{BaO}$ & 0.55 & 0.09 & 0.09 \\
\hline
\end{tabular}

Silika yang terdapat di alam, memiliki keadaan yang tidak murni sehingga untuk mendapatkan silika dalam suatu material dilakukan cara pemisahan dan dilanjutkan dengan pemurnian dari unsur-unsur lainnya yang terkandung dalam sampel. Pada dasarnya pemurnian silika dapat dilakukan dengan cara melarutkan kandungan unsur-unsur seperti $\mathrm{Fe}, \mathrm{Ca}, \mathrm{Al}$ dan logam pengotor lainnya menggunakan pelarut asam. Pelarut asam yang biasa digunakan untuk pelarutan unsur-unsur logam pada sampel adalah $\mathrm{HNO}_{3}$ dan $\mathrm{H}_{2} \mathrm{SO}_{4}$ dan $\mathrm{HCl}$ yang telah dipelajari pada beberapa penelitian, seperti yang dilakukan oleh Adjiantoro pada tahun 2010 dengan menggunakan metode pelarutan asam menunjukkan bahwa keefektifan larutan asam yang paling tinggi untuk menurunkan kandungan pengotor logam adalah $\mathrm{HCl}$.

Pada data tersebut didapatkan kadar silika (SiO2) dengan larutan $\mathrm{HCl}, \mathrm{HNO}_{3}$ dan $\mathrm{H}_{2} \mathrm{SO}_{4}$ masing-masing sebesar $80.23 \%, \quad 77.23 \%$ dan $76.89 \%$. Kadar silika dengan larutan $\mathrm{HCl}$ lebih tinggi daripada data yang didapatkan dengan larutan $\mathrm{HNO}_{3}$ dan $\mathrm{H}_{2} \mathrm{SO}_{4}$. Jumlah logam yang dapat dihilangkan menggunakan $\mathrm{H}_{2} \mathrm{SO}_{4}$ lebih rendah dari $\mathrm{HCl}$ dan $\mathrm{HNO}_{3}$. Hal ini dapat disebabkan logamik sulfat yang terbentuk tidak mudah larut dalam air sehingga $\mathrm{H}_{2} \mathrm{SO}_{4}$ tidak cocok untuk menghilangkan beberapa jenis logam yang terdapat dalam abu vulkanik tersebut. Widyabudiningsih meneliti pelarut yang cocok dalam proses pelarutan aluminium menggunakan variasi asam yaitu asam klorida $36 \%$, asam klorida $18 \%$, asam sulfat $98 \%$ dan asam nitrat $70 \%$ dengan suhu $27^{\circ} \mathrm{C}$ dan $60^{\circ} \mathrm{C}$, menyatakan bahwa pada asam klorida $36 \%$ dan $18 \%$ dengan masing-masing suhu tersebut melarutkan aluminium dengan sempurna, pada asam sulfat dan asam nitrat, aluminium tidak larut sempurna dan berjalan dengan lambat1 4,15 yang mana merujuk pada teori bahwa asam klorida encer dengan mudah melarutkan logam aluminium, pelarutan lebih lambat dengan asam sulfat dan asam nitrat13. Jika logam pengotornya masih tinggi tertinggal dalam abu vulkanik, maka pelarut kurang efektif untuk digunakan. Penelitian dengan variasi asam tersebut menunjukkan $\mathrm{HCl}$ merupaka asam yang paling efektif digunakan untuk menghilangkan logam dari abu vulkanik. ${ }^{2,3}$

Pemurnian dalam kondisi asam bertujuan untuk mengeliminasi kandungan logam dan non logam yang terkandung dalam abu vulkanik. Asam yang digunakan untuk proses pemurnian adalah asam klorida $(\mathrm{HCl}) 12 \mathrm{M}$. Konsentrasi asam yang lebih tinggi menyebabkan semakin banyak impuritas yang dieliminasi sehingga silika yang dihasilkan lebih murni. Pada proses pemurnian ini menggunakan asam klorida dengan konsentrasi tinggi yaitu 37\%. Hal ini akan menguntungkan untuk mendapatkan silika dengan kadar yang murni dikarenakan kandungan unsur - unsur yang dianggap pengganggu dapat larut dalam 
pelarutasam sedangkan silika tidak dapat larut. ${ }^{9}$ Asam klorida merupakan senyawa asam kuat yang stabil dan mudah larut atau dapat berdisosiasi penuh dalam air sehingga sering digunakan dalam analisis kimia untuk mendestruksi sampel analisis. ${ }^{8}$

\section{Kesimpulan}

Berdasarkan hasil dari penelitian ini dapat disimpulkan bahwa larutan $\mathrm{HCl}$ merupakan pelarut yang paling efektif dari pada larutan $\mathrm{HNO}_{3}$ dan $\mathrm{H}_{2} \mathrm{SO}_{4}$. Terbukti dengan hasil XRF yang dihasilkan dari masing-asam mineral tersebut, $\mathrm{HCl}$ sebesar $80,23 \%, \mathrm{HNO}_{3}$ sebesar 77,23\% dan $\mathrm{H}_{2} \mathrm{SO}_{4}$ sebesar $76,89 \%$.

\section{Referensi}

1. Barasa. R.F. Rauf. A. \& Sembiring. M. (2013). Dampak Debu Vulkanik Letusan Gunung Sinabung Terhadap Kadar $\mathrm{Cu}, \mathrm{Pb}$, dan B Tanah di Kabupaten Karo. Jurnal Online Agroteknologi. Vol. 1(4), 1288-1295.

2. Chakraverty A. Mishra. P. and Banerjee D. (1988). Investigation of Combustion of Raw and Acid Leached Rice Husk for Production of Pure Amorphous White Silica. Journal of Material Science. Vol. 23, 21-24

3. Girsang, T.A.S., Apriyani, V., Pasaribu, D.S.N. \& Simatupang, L. (2019). Application of Humid Silica Plus Fertilizer with Various Combination of Planting Media. Indonesian Journal of Chemical Science and Technology, 2(2): 121-124.

4. Ginting. R.D. Simamora.W.S. Ramadhan. A. \& Simatupang. L. (2018). Pengaruh Metode Perendaman dan Refluks Dalam Meningkatkan Kadar Silika Abu Vulkanik Gunung Sinabung. Vol 12(2), 84-92.

5. Lesbani. A. (2011). Studi Interaksi Vanadium dan Nikel dengan Pasir Kuarsa. Jurnal Penelitian Sains.14(4), 14410.

6. Nakada. S. dan Yoshimoto. M. (2014). Eruptive Activity of Sinabung Volcano in 2013 and 2014. Earthquake Research Institute. The University of Tokyo.

7. Norsuraya. S. Fazlena, H. \& Norhasyimi. R. (2016). Sugarcane Bagasse As A Renewable Source Of Silica To Synthesize Santa Barbara Amorphous-15 (SBA-15). Procedia Engineering. 148: 839-846.

8. Roy G. M. (1985). Actived Carbon Spplication in The Food and Pharmaceutical Industries. Lancaster: Tanchnomic.

9. Shcherban. S. Rayzman. V. and Pevzner. I. (1995). Technology of Coal Fly Ash Processing into Metallurgical Properties of Fly Ash-Based Geopolymers. Colloids and Surfaces.
Physicochemistry Engineering Aspects. Accepted Manuscript.

10. Simatupang. L. dan Devi.(2016). The preparation and characterization of Sinabung volcanic ash as silica based adsorbent. Jurnal Pendidikan Kimia. Medan .

11. Simatupang. L. Siburian. R. Sitanggang. P. Doloksaribu. M. Situmorang. M. dan Marpaung. H.(2018). Synthesis and Application of Silica Gel Base on Mount Sinabung's Fly Ash For Cd(II) Removal With Fixed Bed Column. Rasayan J.Chem. 11(2), 819-827.

12. Sriyanto. S. (2017). Kajian Pengaruh Jenis Asam Pada Pemurnian Abu Sekam Padi. Jurnal Avogadro. 1(1).

13. Svehla. G. (1985). Vogel Buku Teks Analisis Anorganik Kualitatif Makro Dan Semimikro Edisi ke Lima. PT. Kalman Media Pusaka. Jakarta

14. Widyabudiningsih. D \& Widiastuti. E. (2015). Studi Awal Pengambilan Kembali Aluminium Dari Limbah Kemasan Sebagai Alumina. Jurnal Fluida. Vo. 11 (1), 42-43

15. Apriyani, V., Girsang, T.A.S., Sirait, R.J. \& Simatupang, L. (2019). Combination of Sinabung Volcanic Ash and Humic Acid Against Characteristics of Humid Silica Fertilizer. Indonesian Journal of Chemical Science and Technology, 2(7): 108-110. 